\title{
The Learning Affordances of a Facebook Environment
}

\author{
Craig Blewett \\ Wayne Hugo
}

\begin{abstract}
Facebook is the most widely used website in the world and its impact on social connections, information dissemination, and now education, is being keenly felt. This research seeks to explore how students learn in a Facebook environment using an affordance based theoretical lens. An ethnographic case study approach was used to explore how $4^{\text {th }}$ year university students, doing a module on Computer Mediated Communication, used Facebook. The research identified 11 affordances that are arranged around an Actant-Activity Affordance framing. This framing allows for the affordances to be both explored across two dimensions and also the interactions between the affordances. These interactions between affordances reveal the importance of a new approach to affordance-based research into learning, where affordances are not considered in stasis but rather in relation to competing attractions and resistances.
\end{abstract}

Keywords: e-learning, Facebook, affordances, ethnography, actants

\section{Introduction}

It is becoming increasingly important to discover how learning takes place in online environments. 'More and more instructors are beginning to abandon traditional approaches to instruction ... for cutting-edge strategies, which allow students to construct their own learning' (Heider et al. 2009). However, at the moment most approaches 'are still based on a tool-paradigm ... (where) technology is seen as a medium for delivering precast instructional content faster, cheaper, better managed and better targeted' (Lindner 2006). If online 
learning is going to be explored, then simply replicating offline practices in online environments is likely to mask the opportunities and approaches within online learning.

One solution to this is to adopt an affordance-based approach to exploring online learning environments. An affordance-based approach fundamentally alters the way in which the research is undertaken from one based on features to one based on action opportunities. Rather than exploring what an online environment is designed to do, an affordance approach seeks to explore the affordances that arise, whether intentional or unintentional. Often it is in the unintentional affordances that the greatest insights can be gained into how learning takes place.

This article seeks to explore learning within a Facebook learning environment and to answer the critical question - What are the affordances of a Facebook learning environment?

\section{Literature Review}

This research focuses on the use of Facebook, a Social Network System (SNS) as a learning environment. While SNSs were designed primarily to allow people to connect, their applications have begun to extend into other areas such as politics, cultural studies, and more recently education. Facebook represents the single biggest example, not only of a SNS but of any online website. Facebook, which started in 2004, had 1.32 billion monthly active users as of June 30, 2014 (Facebook 2015) making it the largest single website, according to membership, on the World Wide Web.

The impact of the growth in Facebook is reflected in the recently increasing interest in Facebook's use for education. In 2010 de Villiers reported that there 'is a low level of use of Facebook for academic purposes in the South African academic community' (DeVilliers 2010: 175). However, more recently, Rambe indicated that Facebook is increasingly being used in South Africa by users 'for the exchange of resource and informal learning' (Rambe 2012: 295).

However, while there appears to be a move towards using Facebook for learning, the focus has been on Facebook's support for open discussion, while the role of learning is still largely supported by official university learning management systems such as Moodle (Rambe 2012). This led Rambe 
to conclude that Facebook is 'about artefact sharing, academic networking and relationship building' (Rambe 2012: 299).

As such, Facebook usage by universities, and research into Facebook usage, has centred around issues of networking, relationships, motivation etc. and not on learning per se. In fact some studies have suggested that teachers should remain passive, rather than active when interacting with students on Facebook (Teclehaimanot \& Torey 2011).

\section{Affordance Theory as a Theoretical Lens}

It is the theory which decides what can be observed (Albert Einstein)

Researchers have brought a range of theoretical lenses to bear on research related to social networks and Facebook, such as Activity Theory (Rambe and Ng'ambi 2011), Communities of Practice (Williams et al. 2011), and Affinity Spaces (Lammers et al. 2012). While all of these provide useful perspectives into interaction and design issues, this research uses affordance theory with its focus on action possibilities.

Affordances, according to Gibson's (1982) original conception of them, are action opportunities that exist in the environment. 'The affordances of the environment are what it offers the animal, what it provides or furnishes, either good or ill' (Gibson 1979). Adopting an affordance-based perspective fundamentally alters the way in which the research is viewed from one based on features to one based on action opportunities.

'Facebook features are designed to trigger social behaviour, not create it .... Facebook and Twitter aren't social software systems, they are systems that afford certain social behaviour' (Appleseed 2013 para. 1). One of the key challenges of undertaking an exploration of learning in a new learning environment, such as Facebook, is the suspension of epistemological and pedagogical perspectives. Observing how learning takes place in a physical and social environment, such as Facebook, requires a lens that allows more than a simple feature-based view of the environment, but rather one that provides an insight into determining how the environment affords learning.

Affordances focus on action opportunities, rather than features, which typically reflect designer intentions, and therefore it provides a useful 
perspective of how learning takes place in Facebook (Parchoma 2013). In addition, affordances are not concerned with 'judging' one environment above another, but rather exploring the action opportunities that an environment offers to the students. However, understanding how affordances operate does not go uncontested (Parchoma 2013), and as such a brief discussion of how affordance theory is used in this research is necessary.

Affordance theory, while originating with Gibson (1977) was extended (or adjusted) by Norman (1988), and then further impacted by others. The first movement, Object Affordances, as originally conceptualised by Gibson (1977) is grounded in a positivist ontology (Parchoma 2013) that suggests the objective and inherent affordances offered by an environment to the actor (Oliver 2005). The affordances are there in the environment, whether taken up or not.

The second movement, primarily conceptualised by Norman (1988), saw an attempt to remain ontologically aligned with the first movement's realist perspective but at the same time frame affordances within an interpretivist paradigm, thereby creating an interpretivist-realist dilemma (Oliver 2005). The nub of the issue revolved around whether a subject needed to pick up on the affordances within the environment for the affordances to be really there, similar to the 'if a tree falls in a forest and no-one witnesses the fall then can it really have fallen' debate.

The third movement can be seen as a response to calls to move away from subject-object and agency debates that have defined both the first and second movements of affordances (Sanders 1997; Williams \& Edge 1996). However, it is not until more recently that developments in social theory have provided potentially appropriate framings to make this next move. Particularly useful is Latour's (2005) actant perspective that argues against the object/subject dichotomy in favour of a construction that takes place between equally active objects and actors, termed actants (Alvesson \& Sköldberg 2009).

The third movement is therefore a framing of affordances in terms of the 'in between' rather than one or other side. While carrying over elements from the second movement's interpretivist/constructivist approach, this third movement extends the framing to embrace the environment (technology) as an equal actor in the construction of the affordance, as espoused by the first movement. Hence, this third movement elevates the role of connection in affordances between equally real and enabled actants. 
As such, Actant Affordances are what is implied in this research by affordances and is defined as actant action opportunities arising out of interactions, existing in the network of relations, and are co-dependent on the environment and actor.

Affordances provide a 'particularly attractive, framework for investigating salient questions about design and use of networked learning environments, despite (the) ongoing ontological debates' (Parchoma 2013). This research will use this new actant affordance theorisation as the framing lens to explore the use of Facebook for learning, with its focus on the space between.

\section{Research Methodology}

The best laid schemes of mice and men... (Robert Burns).

This research seeks to answer the question - What are the affordances of a Facebook learning environment? While there are a wide range of approaches that could be followed, this research adopted an ethnographic case study approach. Rybas \& Gajjala (2007) in their study of Facebook, say that 'cyberethnographic engagement plays into the critical research agenda of examining the contextual manifestation of oppression'. They see cyberethnography as being based on an epistemology of doing, which resonates with the critical framing of this research, and our embedded role within the environment (explained below). So while this study involves a single case it is not a classic, positivist case study, but rather an ethnographic case study approach.

The research focuses on the learning experiences of a $4^{\text {th }}$ year (Honours) Information Technology class, Computer Mediated Communication (CMC). The CMC course was purposefully chosen as the course involves $4^{\text {th }}$ year students who are familiar with technology, and as such issues of technophobia were unlikely to arise, and students would most likely be familiar with, and comfortable in Facebook. As this research is focused on learning in Facebook, and not on technology adoption, it was important to use a group who were already comfortable in the technological space.

The CMC class consisted of 38 students, 2 lecturers and 1 tutor. However, in addition to this, due to the open nature of the Page, students from 
other modules, friends of students, and lecturers from other modules also participated on the Facebook Page.

A Facebook Page, as opposed to a Group was set up, called 'Fab Space' and hereafter referred to as Fabspace. The main source of data for this research is the activity within this Page. Fabspace contained 663 Posts and 1820 Comments, a total of 2483 content units. This also includes 52 comments from people external to the course.

In addition to Fabspace, two other sources of data were also used. The first were transcripts from two virtual focus group (VFG) discussions that took place (at the beginning and end of the course) and the second are student reflections as recorded in reflective journals (RJ).

The Analysis was divided into two parts. The first part made use of the three initial focus group transcripts and the literature to develop seed affordance categories. The second part of the seed category analysis was to then compare the list emerging from the data with those identified in the literature to see what categories were not identified by the analysis or were identified in the analysis and not the literature. This process resulted in a comparative list of affordances that served as seed categories for the analysis and coding of the Fabspace data set.

This first step of the analysis identified potential affordance categories based on both the student expectations arising from the focus group and the literature. The second step of the analysis involved using these seed categories and analysing the actual student usage of Facebook as reflected in the activity within Fabspace. This process resulted in coding 13368 elements and identifying 279 codes.

Thereafter a process of merging and cleansing code categories was undertaken which resulted in a final list of 65 codes. These codes were then consolidated further, after comparison with the codes arising from the Part 1 analysis and this resulted in a list of 11 affordances (discussed below).

\section{Facebook Affordances - Analytical Model}

Most researchers reporting on technological affordances tend to produce lists of affordances that are not arranged around any obvious framing. While there are some similarities between these lists, there is no organizing mechanism as Oliver (2005) points out in his critique of the use of affordances - 'there seems to be no unifying concept behind the list(s)' (p. 409). 
A simple matrix was developed by the authors, building on extant frameworks such as McLoughlin and Lee's (2008) Pedagogy 2.0 framework, Wang's (2005) Cybergogy, and Scopes' (2009) extended Cybergogy framework. A basic distinction between activities based around what is said (words) or what is done (works) within Facebook was made. A second basic distinction was made between actions that either solidify the connection between actants (people and environmental) or open the space between actants.

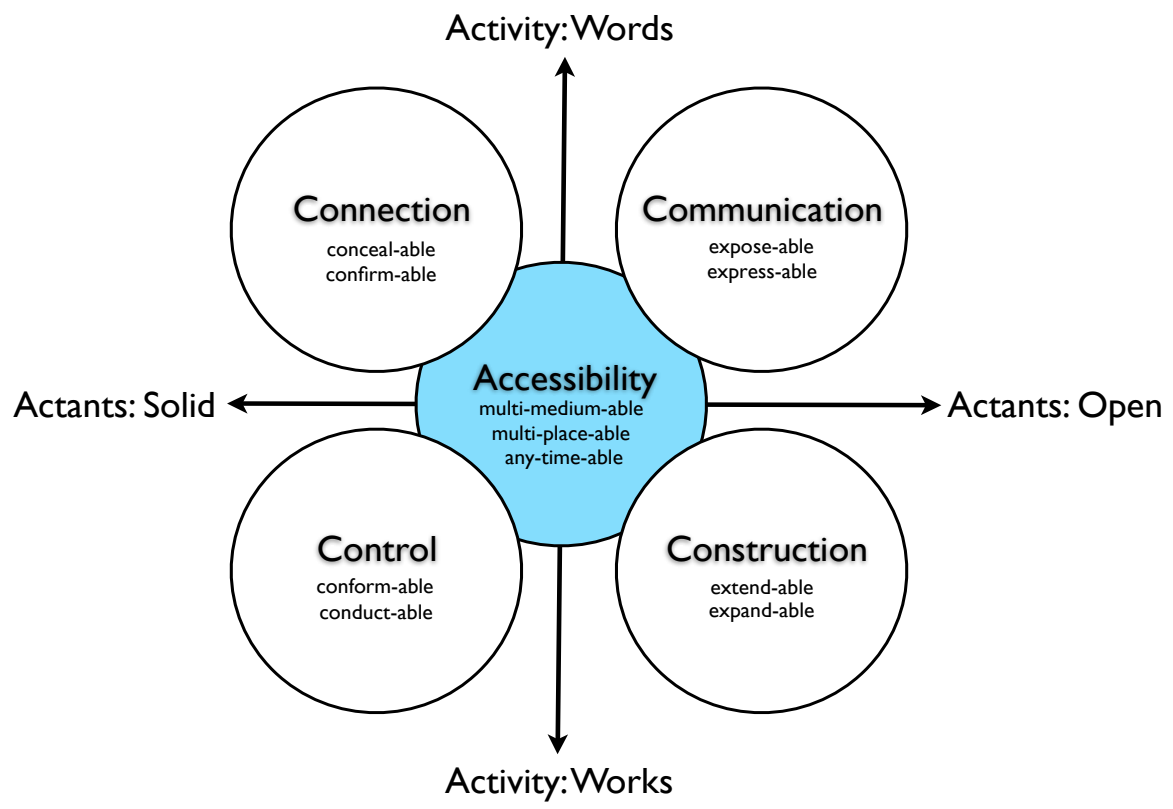

\section{Figure 1: Actant-Activity Affordance framing}

The affordances discussed in this analysis are categorized between two axes, the first being an Activity axis, that tends either towards the activity being word based or towards works/ action based. In online social spaces such as Facebook, most activity is around what is said, i.e. the words. 'Words' is used in a broad sense, not limited merely to text but includes the use of various word proxies such as emoticons, Like button, images, etc. Works are the activities users do in online social spaces such as creating spaces, customizing the environment, uploading content and other artefacts, and so on. 
The second axis, the Actant axis, tends either towards solidifying actants' connections or opening actant choices. Actants are deemed to tend towards solidifying when they draw together through words or become tangible through works. Actants are deemed to tend towards opening when they expose or share through words or expand and extend actant spaces through works. This mapping of actants between solid and open not only frames a categorization but also depicts tensions that lie between affordances where the tendency of an affordance to open is resisted by the tendency of another affordance to solidify. This interconnectedness of affordances will be explored in the discussion below.

Using this categorisation it is possible to position the affordances discussed below in the following Actant-Activity Affordance framing.

The five level 1 affordances, arising out of the analysis of the Fabspace transcript, were as follows;

- Accessibility affordance: The central affordance, Accessibility, refers to the ability to gain access to the learning space. This is central to realising the other four affordances.

- Connection affordance: The connection affordance refers to action opportunities that tend towards solidifying the connections between actants by either removing barriers to connecting or by strengthening connections.

- Communication affordance: This affordance relates to action opportunities that allow the actants to expose or express themselves within the learning space.

- Control affordance: The control affordance is an affordance that relates to opportunities to control activities in the learning space by imposing or negotiating conformity and affecting changes to the space or other users.

- Construction affordance: This affordance relates to activities that open up the actant space through the construction of additional spaces.

Each of these affordances is discussed in more detail below. 


\section{Accessibility}

The ability to access the Facebook space anytime and anywhere is central to students using the space and hence realising the other four affordances. Accessibility was identified 197 times within the 2483 posts and comments (8\%), which illustrates the importance of this in students' use of the Facebook learning space. The accessibility affordance will be analysed through the three contributing affordances; any-time-able, multi-place-able, and multi-mediumable.

\section{Accessibility - Any-Time-able}

Freedom of time features strongly in both the comments and in an analysis of posting time. Late night and weekend access saw students involved in a range of activity from general chat to late night discussions and debates such as the following;

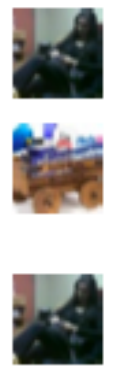

\section{Kaahsifa Ahmed haha Group 3 ROCKS!! ;)}

1 March at 00:54 - Like . 1

Fab Space LOL Kaahs when exactly are u planning to sleep

2day??

1 March at 00:59 - Like

Kaahsifa Ahmed just now lol was answering everyones questions on our discussions. Who am i speaking to btw? 1 March at 01:03 - Like

This accessibility affordance is representative of the temporal relationship that exists between the human and technological actors in this Facebook environment (Parchoma 2013). The environment offers ease of access at any time, an inherent need for the students as depicted in multi-place-able below.

\section{Accessibility - Multi-Place-able}

The second aspect of the accessibility affordance is place. This refers to the range of physical places a student can be and still access the learning environment. The ability to access an online learning environment from anywhere is a key affordance of technology-mediated environments that resulted in comments such as the following: 


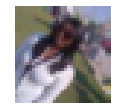

Valencia Amg Pather It was awesome to be at home and work Tehs! Wen we're done, we cn do as we please for the rest of the day! No travelling to campus! Im very thankful! 18 May at $21: 32$. Like

\section{Accessibility - Multi-Medium-able}

The third aspect of accessibility is the medium of access. While Facebook's main portal is web based, it has been optimised for both desktop and mobile access. 67 posts were tagged as 'via Mobile' or 'via Camera+' (a mobile app) or 'via BlackBerry Smartphones App' etc. Affording mobile access to the students extends the ability of the students to engage with the course material from any location and at any time.

Having considered the accessibility affordance and the three contributing affordances (multi-medium-able, multi-place-able, any-timeable) the next sections will look at the four affordances that arise as a result of using the Facebook space for learning.

\section{Connection}

The connection affordance refers to action opportunities that tend towards solidifying connections between actants by either removing barriers to connecting, or strengthening connections. An analysis of the student usage of Facebook reveals that this affordance consists of two key affordances that together assemble to offer the connection action potential, viz. conceal-able and confirm-able.

\section{Connection - Conceal-able}

The conceal-able affordance specifically indicates the usefulness of adopting an affordance framing rather than a feature-based perspective. This affordance is not a design intention of a Facebook Page but rather an unintentional affordance.

As all students were given administrator privileges to Fabspace, so they could add applications and edit the Page, the result was that by default they all posted as the Page name (Fab Space) rather than their own username. While it was possible to change to post as the username, students now had a 
conceal-able affordance that afforded the students an opportunity to conceal their identity, thereby reducing concerns of 'looking silly' or fearing consequence as a result of challenging others (lecturers included).

While all members of the Facebook Page started out as anonymous (posting as the generic FabSpace) most changed their name (28) with some (12) remaining anonymous the entire course.

Anonymity afforded by Facebook enabled students to ask questions of the lecturer that they might have felt uncomfortable asking. The following is an example of a student using this affordance to ask for an extension to a project deadline.

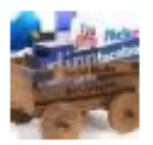

\section{Fab Space}

can we plz get an extension for the WW build, honours is bliss bt ryt nw its torture

While this conceal-able affordance provided a way for students to express themselves, it was not always accepted. Students even went so far as to insist that other students reveal who they are, or as one student put it, 'to man up' and use their real name.

\section{Connection - Confirm-able}

The second affordance contributing to the connection affordance is confirmable. While face-to-face communication allows for the use of various nonverbal cues such as nodding of the head or verbal cues such as 'yes', 'uh-huh', etc. to indicate confirmation or affirmation during a conversation, this need is fulfilled in several other ways in Facebook.

The easiest, and often used way of doing this in Facebook, is clicking the Like button in response to a post or comment as depicted below.

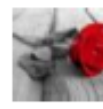

Tehseena Meer I don't think its the best marketing way but at least the homeless people can earned money, Its like R60 an hour which is quite a lot.

13 March at 17:06 - Like . 2

Doing this results in a count being displayed ( 2 people Liked the above comment). $19 \%$ (472 of 2483) of the posts/comments in Fabspace had one or 
more Likes associated with them indicating the extent to which this confirmation/head-nod was used.

While both the confirm-able and conceal-able affordances contribute to solidifying actant connections there is however a tension between them. While the conceal-able affordance affords freedom of expression it can result in less confirmations. In the following example Ebrahim enquires as to who has Liked his post, illustrating the relationship between identification and confirmation.

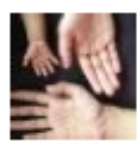

\section{Ebrahim Hassan Adam}

The look on peoples' faces when you tell them you study an Honours course based on Facebook :D

Like - Comment - 23 February at 08:13 .

Fab Space likes this.

Ebrahim Hassan Adam whose FaB Space?

23 February at 08:24. Like

So, while both these affordances tend towards solidifying, the confirmable affordance is resisted by the conceal-able affordance.

\section{Communication}

The second set of affordances is the Communication affordances. These affordances relate to action opportunities that allow the actants to expose or express themselves within the learning space. Unlike the connection affordance that tends towards solidifying connections between individual actants, this affordance seeks to open actants to multiple others, both those within and without. The assemblage of affordances that contribute to the communication affordance are the expose-able and express-able affordances.

\section{Communication - Expose-able}

In Facebook there is an ebb and flow of information between various spaces, such as the Facebook Page, a member's home page, Groups, etc. The result is that, depending on privacy settings, posts to the Facebook Page are seen in various other places and by a wide range of people (outside of the Page 
members). This resulted in 54 comments in Fabspace originating from nonstudents, as indicated below.

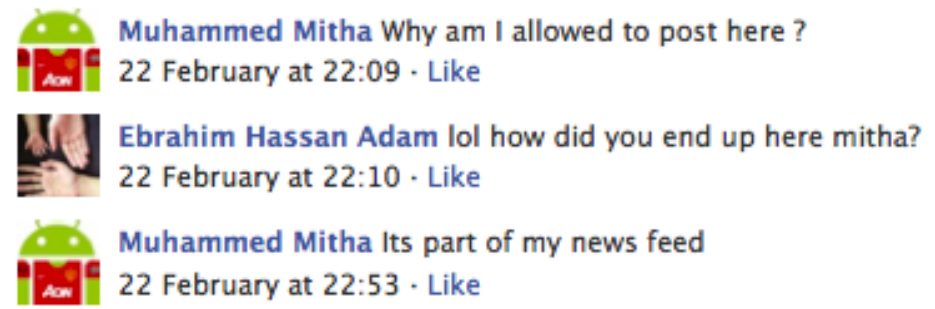

This expose-able affordance resulted in an opening of the space beyond the class, as such drawing in conversation and information from a wide range of people. However, while the expose-able affordance can result in enriching communication it also has the danger of impeding communication either through additional 'noise' or language and behaviour that would not normally be expected in a course context.

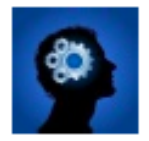

\section{Thabo Manqele}

I think its time we closed our chat rooms now coz Random people have started getting in and they swear as well too

Like - Comment - 23 February at 12:32.

Tehseena Meer its a pity we had to make it public 23 February at $12: 44 \cdot$ Like

The expose-able affordance, while part of many online environments is not expected in learning environments. Learning is traditionally seen as closed and students are only exposed to those who are part of the course.

The expose-able affordance enables students to easily see content in a single space by creating bi-directional flows between multiple spaces whether private, social, educational, etc. However, this affordance exists at tension with itself, whereby on the one hand it affords a form of content singularity, a convenience, yet on the other hand it can result in content being exposed to those for whom it was not intended. 


\section{Communication - Express-able}

The second affordance contributing to the Communication affordance of Facebook is the express-able affordance. This describes the action opportunity for students to express themselves through Facebook.

Hugo (2013) discusses multiple pedagogic variables that can be brought to bear in a multiplicity of combinations, in understanding the educational space. Three of these pedagogic variables that can be manipulated are selection, sequence and pacing. A solid instantiation of the variable indicates no choice whereas an open instantiation indicates wide choice. Using this as a frame it is possible to explore how the express-able affordance of Facebook opens up the selection, sequence and pacing variables despite a formalised (solid) curriculum and content.

In terms of selection, the content of the course was clearly framed (solid) however there was lots of evidence of posts both on the core course content and on other topics. An analysis of the 663 posts reveals that $62 \%$ (408) were about core content, while $38 \%$ (255) were non-core content posts.

In terms of sequence, there was also little flexibility in the course structure (solid). However, as mentioned earlier, Facebook preferences conversations that have had recent activity through Likes or comments, over those with no activity. This results in these conversations rising in the stream and appearing on the walls of members of the Page. As a result of this, the sequencing of the engagement with the content is controlled by the students' engagement with the posts. This resulted in topics that were considered 'past', re-entering the conversation space.

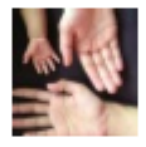

\section{Ebrahim Hassan Adam}

Will post my response tomorrow (tired now)...

http://www.itweb.co.za/index.php?

option=com_content \&view $=$ article\&id $=51634 \% 3$ Atimeline-forbrands-comi

www.itweb.co.za

\section{Like - Comment - Share - 16 February at 23:47 .}

In terms of the third pedagogic variable, pacing, this too could be deemed as solid in that the dates for various activities were clearly delineated. However as both the creation and consumption of course content was 
determinable by the students, they were also able to have some control over pacing. For example in this post the student shared some content but chose to deal with the content in more detail at a later stage.

So, for all three variables, selection, sequence, and pacing, the environment afforded an opening of the pedagogic space. In addition to these variables Facebook also provided opportunities for students to express themselves in their native languages or to include rich content (images, videos, etc.).

As with the expose-able affordance, the express-able affordance sits in a network of attractions and resistances. On the one side it attracts affordances such as conceal-able, confirm-able while on the other side resisting affordances such as conduct-able.

\section{Control}

The third set of affordances is the Control affordances. These affordances relate to opportunities to control activities in the learning space by modifying the environment or controlling what people do. This affordance consists of the conform-able and conduct-able affordances, as discussed below.

The conform-able affordances are the action opportunities that exist to get users to agree to a course of action. The conduct-able affordances are the action opportunities to act on both the users and the Facebook space. These two affordances sit in relation to one another where conduct-able is 'me doing what I want' and conform-able is 'me convincing you to do what I want'. The interplay between these affordances shows how the Control affordance sits in relationship both to itself and with other attracting and resisting affordances. The relation between the conform-able and conduct-able affordance is so intertwined that both of them will be presented together in the discussion below.

\section{Control-Conform-able and Conduct-able}

The Facebook Page, as already discussed, was setup to provide a democratised learning environment whereby all users were equal. Any user of the space could make any changes to the space they deemed necessary but this would also impact the experiences of their fellow users. This sets the predilections of one person's conduct-able affordance at tension with another's, unless the conform-able affordance is successful enacted. 
The following example depicts a student jokingly brandishing her admin rights as a threat to a fellow student.

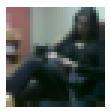

Kaahsifa Ahmed Remember that I have admin rights and can delete your submissions boy...

25 February at 06:05 - Like

In addition to the joke, this comment indicates the intra-affordance tension that exists within the conduct-able affordance. The student that Kaahsifa is referring to has equal rights to delete her submissions and even her membership of the Page. And so the conduct-able affordance exists at tension with itself amongst the various members.

An interesting effect of this intra-affordance tension is that the students were cautious with acting on this affordance. The result was that students acted on the conform-able affordance to try and negotiate agreement before acting on the conduct-able affordance as illustrated with the profile image decision below.

As all students could edit the Page, one of the elements they could set was the Page profile image. The students attempted various approaches to getting agreement on an image, such as launching a Poll (which received hardly any votes), asking for people's opinion, or threatening to act unilaterally.

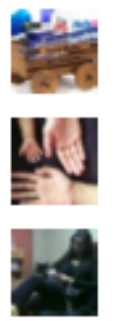

Fab Space Votes for this as profile pic...???

17 February at 09:40 - Like

Ebrahim Hassan Adam In favour :P

17 February at 15:42 - Like

Kaahsifa Ahmed No one is saying anything!!! Should i put it up anyways??? I AM ADMIN after all 8-) lol

17 February at $18: 12$ - Like

Here Kaahsifa is saying that she can act on the conduct-able affordance should she wish to. Kaahsifa commented on the tension between the conductable and conform-able affordances in the Focus Group discussion.

Kaahsifa: u know i was thinking can i change the profile pic?? then $i$ was like but what if the others dont like it then i just left it lol (P3:169). 
So, while on the one hand the conduct-able affordance imbued the students with control, acting on it, preferences one choice over another and hence solidifies the actant's action. The conduct-able affordance therefore sits both at tension with itself and the related conform-able affordance offered by Facebook.

\section{Construction}

The final set of affordances is related to the actant's ability to construct the space and hence extend and expand actant opportunities. The construction affordance speaks to the actant's ability to add to the learning space through apps and other spaces and hence construct their learning environment. Within Facebook the construction affordance is an assemblage of two main affordances, viz. the extend-able and expand-able affordances. The extend-able affordance relates to extending the functionality of Facebook through the use of apps (applications) while expand-able affordance refers to being able to expand the space into a variety of other self-created spaces within Facebook.

\section{Construction - Extend-able}

Facebook offers a wide range of applications that are 'designed to enhance your experience on Facebook with engaging games and useful features' (Facebook 2013 para. 1). As Page admins the students had the ability to add applications to the page and thereby extend its functionality.

During the course 6 apps were added; three were installed by the lecturer and three by a student. However, none of the student added apps were ever used. So, while Facebook affords the opportunity for users to extend its functionality through apps, and thereby potentially uncover additional affordances, there was nonetheless limited use of this extend-able affordance in the course. This seems to indicate that rather than extending Facebook's inherent and internal native functionality, students chose rather to respond to the affordances immediately enactable within the Facebook ecosystem. The extend-able affordance is resisted by both familiarity and other affordances such as the expose-able affordance, as activity within these extended app spaces is not automatically curated back into the Facebook feeds and the ongoing interactions. 


\section{Construction - Expand-able}

Facebook provides a number of spaces outside of the user's home page that can be used to communicate, collaborate and organise, such as Groups, Pages, and Events. During the course students set up a variety of other spaces in which to interact. Some used Pages for group work, while others made use of Facebook Groups.

While the expand-able affordance allowed for groups to create other spaces to learn in, it does push against other affordances. For example it is resisted by the conduct-able affordance in that there is less control of being able to get members into the Group as shown below.

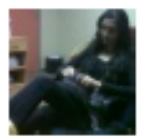

\section{Kaahsifa Ahmed}

Group3 peeps! Ima be hitting yourl with an invite. Accept OR DIE :) Like - Comment - 24 February at 16:00 .

It is also resisted by the expose-able affordance, as posts in private Groups/Pages will not appear back on the main page. The extend-able and expand-able affordances provide action possibilities for users to increase the range of potential affordances of the Facebook environment. However, as with the other affordances these affordances sit in a network of relationships that both attract and resist the other affordances. These affordances also resonate with the 'openness' principle of Connectivist learning, and both the inclusion of others into the learning discussion and the ability to navigate multiple networks outside of the immediate course network.

\section{Actant-Activity Affordance Network}

The Actant-Activity Affordance model presented above provided a framing for exploring the various affordances in stasis, however what became clear in the analysis was that affordances do not exist in isolation but in a tension of attracttions and resistances with other affordances. So while an affordance provides actant action opportunities these action opportunities must be considered in relation to the network of action opportunities presented by the space.

In a similar way to quantum physics' uncertainty principle, that states that the position and momentum of a particle cannot be known at the same time (Hilgevoord \& Uffink 2012), it is not possible to map the position and 
momentum of the affordances at the same time. So while the Actant-Activity model provides a useful framing for positioning the affordances it does not depict the momentum caused by inter- and intra-affordance tensions.

The following diagram (Figure 2) attempts to depict the 'momentum' or network of relationships that exist between the affordances in the ActantActivity affordance network.

\begin{tabular}{|c|c|c|c|c|c|c|c|c|}
\hline 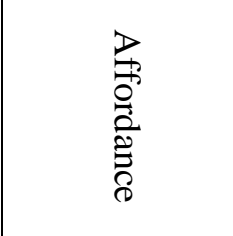 & $\begin{array}{l}0 \\
0 \\
\tilde{\delta} \\
\stackrel{0}{1} \\
\frac{\tilde{\sigma}}{2}\end{array}$ & 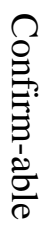 & $\begin{array}{l}\frac{\pi}{x} \\
0 \\
0 \\
0 \\
1 \\
1 \\
\tilde{0} \\
\frac{0}{0}\end{array}$ & 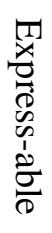 & 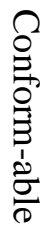 & $\begin{array}{l}\Omega \\
\mathscr{2} \\
\frac{0}{0} \\
\frac{1}{1} \\
\frac{\tilde{\sigma}}{0}\end{array}$ & $\begin{array}{l}\frac{\pi}{x} \\
\stackrel{0}{0} \\
\stackrel{0}{0} \\
\frac{1}{1} \\
\frac{\tilde{\sigma}}{0}\end{array}$ & 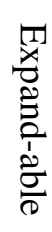 \\
\hline Con & -1 & -1 & -1 & 1 & 0 & 1 & -1 & 0 \\
\hline Confirm-able & -1 & -1 & 1 & -1 & 1 & 1 & -1 & 1 \\
\hline Expose-able & -1 & 1 & -1 & 0 & -1 & -1 & 0 & 1 \\
\hline ss-able & 1 & 1 & 0 & -1 & 1 & -1 & 1 & 1 \\
\hline Conform-able & 1 & 1 & -1 & 1 & -1 & -1 & -1 & -1 \\
\hline Conduct-able & 1 & 1 & -1 & -1 & -1 & -1 & 0 & 0 \\
\hline Extend-able & -1 & -1 & -1 & 0 & -1 & 0 & -1 & 1 \\
\hline Expand-able & 0 & 1 & 1 & 1 & -1 & 0 & 1 & -1 \\
\hline
\end{tabular}

KEY

-1: Resistor

1: Attractor

0: Attractor \& Resistor

\section{Figure 2: Actant-Activity Affordance Network}

Some affordances resist one another (-1), where acting on one affordance is resisted by another affordance, while other affordances attract one another (1), where acting on one affordance encourages acting on the other affordance. For example, the confirm-able and conceal-able affordances tend to resist one another. Choosing to post anonymously (conceal-able) caused less Like's (confirm-able) of posts and often resulted in requests for an unmasking 
of the identity. However, the conceal-able affordance attracts the express-able affordance as it provided more opportunities to make comments to both fellow students and the lecturer in an incognito manner.

Some of the affordances exist in both a resisting and attracting relationship at the same time, e.g. the expose-able and extend-able affordances. On the one hand the extend-able affordance opens up new opportunities and spaces for the students to be exposed to the 'outside' through the use of apps. However, at the same time these external apps do not always integrate into the feed of the Page and hence push against the automated curation that is central to the expose-able affordance.

Interestingly, two of the affordances, expose-able and conduct-able, exist in an intra-affordance tension with themselves. This means that acting on the affordance can be resisted by others also acting on the same affordance. For example a student considering enacting the conduct-able affordance to make a change to the Page weighs this against other students enacting the conduct-able affordance and also making changes to the Page.

What is clear from this network is the complex interplay between affordances, attracting, resisting, and attracting and resisting both one another and themselves. This network of affordances, in a web of competing attractions and resistances, is the set of action opportunities that students in the Facebook space activate as part of their learning experience.

Understanding student use of this Facebook environment for learning needs to be framed by the interconnected nature of the network of affordances, and not simply by individual affordances. This also illustrates that a connectivist-based view of learning which espouses a network perspective, is not only limited to the internal neural networks, and the external technological network, but also includes a network of affordances that also attract and resist, thereby impacting how learning is experienced. As Siemens (2004) argues, the 'pipe is more important than the content within the pipe' and it might be added that learning to navigate the network of affordances that constitute the pipe is equally important to learning.

\section{Conclusion}

This research set out to determine the affordances that arise from using Facebook for learning. By using an actant-based affordance lens, the research explored student use of a Facebook Page. 
While previous research has identified key affordances arising from using technology for learning, largely in the Critical Realist realm of the empirical, this research points to the need to consider the assemblage of affordances that interact, in the realm of the real, to provide these higher level affordances. As discussed, these affordances do not operate in isolation but in a network of attracting and resisting relationships. So while collaboration is an affordance of Facebook, and other technological environments, the interplay between the assemblage of affordances is important as this impacts the manner in which the collaboration takes place.

Therefore, it is not simply sufficient to assume that Facebook, or any other online environment will afford collaboration, without being aware of how the contributing affordances interact within the environment. Additionally, by considering the real mechanisms at works, key affordances that might be overlooked are identified. For example, simply saying collaboration is an affordance might signal the existence of expose-able, express-able, confirm-able, and conduct-able affordances, however on closer inspection it could, and does, include other affordances too. For example in Facebook (and other environments) the conceal-able affordance plays a key role in collaboration, one that is not mentioned by any of the above research. In fact, the key role of the confirm-able affordance in collaboration is also not explicitly mentioned, yet it is germane to most collaboration. Yet as discussed in this paper, the conceal-able and confirm-able affordances resist one another, and as such it is important to understand how these affordances therefore interact in their contribution to collaboration.

So while there are similarities to affordances identified in previous research, this research has shown that by identifying the assemblage of affordances in the realm of the real that constitute higher-level empirical 'affordances' a clearer picture of the action opportunities that can be navigated is produced. It becomes apparent that not only are there multiple affordances on offer but that enacting these affordances is itself a process of negotiating a web of interconnected affordances.

\section{References}

Alvesson, M. \& K. Sköldberg 2009. Reflexive Methodology: New Vistas for Qualitative Research. London: Sage. 
Appleseed, J. 2013 Social Media: Analyze Affordances, not Features. Available at: from http://baymard.com/blog/analyzing-social-affordances (Accessed on 9 October 2013.)

Blewett, C. 2014. Learning in a Facebook Environment: The Writing is on the Wall. Doctoral dissertation, University of KwaZulu-Natal, Durban.

de Villiers, R. 2010. Academic Use of a Group on Facebook: Initial Findings and Perceptions. Literature Study General Use by University Students. Paper presented at the Proceedings of Informing Science \& IT Education, 19 - 24 June 2010, Cassino.

Facebook 2013a. Groups for Schools. Available at:

http://www.facebook.com/about/groups/schools

(Accessed on 31 December 2013.)

Facebook 2013b. How are Pages Different from Groups? Which one Should I

Create? Available at: http://www.facebook.com/help/155275634539412

(Accessed on 31 December 2013.)

Facebook 2013c. What is an App on Facebook? Available at: http://www.facebook.com/help/217453588274571 (Accessed on 31

December 2013.)

Facebook 2014. Key Facts. Available at: https://newsroom.fb.com/Key-Facts

(Accessed 14 October 2014.)

Gibson, E.J. 1980. The Concept of Affordances in Development: The

Renascence of Functionalism. Paper presented at the Minnesota symposia on child psychology. Fall 1980, Minnesota.

Gibson, J.J. 1977. Perceiving, Acting, and Knowing: Toward an Ecological Psychology. Hillsdale, NJ: Lawrence Erlbaum.

Gibson, J.J. 1979. The Ecological Approach to Visual Perception. Boston: Houghton Mifflin.

Heider, K., D.A. Laverick \& B. Bennett 2009. Digital Textbooks: The Next Paradigm Shift in Higher Education? AACE Journal 17, 2: 103 - 112.

Hilgevoord, J. \& J. Uffink 2012. The Uncertainty Principle. In Zalta, E.N. (ed.): The Stanford Encyclopaedia of Philosophy. Stanford: Stanford University Press.

Hugo, W. 2013. Cracking the Code to Educational Analysis. Cape Town: Pearson.

Hurt, N.E., G.S. Moss, C.L. Bradley, L.R. Larson, M.D. Lovelace, L.B. Prevost \& M.S. Camus 2012. The 'Facebook' Effect: College Students' Perceptions of Online Discussions in the Age of Social Networking. 
International Journal for the Scholarship of Teaching and Learning 6, 2,10: 1 - 24. https://doi.org/10.20429/ijsotl.2012.060210

Lammers, J.C., J.E.N. Scott Curwood \& A.M. Magnifico 2012. Toward an Affinity Space Methodology: Considerations for Literacy Research. English Teaching: Practice and Critique 11, 2: 44 - 58.

Latour, B. 2005. Reassembling the Social - An Introduction to Actor-network. Oxford, Oxford University Press.

Laurillard, D., M. Stratfold, R. Luckin, L. Plowman \& J. Taylor 2000. Affordances for Learning in a Non-linear Narrative Medium. Journal of Interactive Media in Education 2000, 2: Art. 2.

https://doi.org/10.5334/2000-2

Lindner, M. 2006. Use these Tools. Your Mind will Follow. Learning in Immersive Micromedia and Microknowledge Environments. Paper presented at The Next Generation: Research Proceedings of the $13^{\text {th }}$ ALTC conference, 5 - 7 September 2006, Edinburgh.

Loving, M. \& M. Ochoa 2011. Facebook as a Classroom Management Solution. New Library World 112, 3/4: 121 - 130.

https://doi.org/10.1108/03074801111117023

Norman, D.A. 1988. The Psychology of Everyday Things. New York: Basic Books.

Oliver, M. 2005. The Problem with Affordance. E-Learning and Digital Media 2, 4: 402 - 413. https://doi.org/10.2304/elea.2005.2.4.402

Parchoma, G. 2014. The Contested Ontology of Affordances: Implications for Researching Technological Affordances for Collaborative Knowledge Production. Computers in Human Behavior 37: 360 - 368.

https://doi.org/10.1016/j.chb.2012.05.028

Rambe, P. 2012. Critical Discourse Analysis of Collaborative Engagement in Facebook Postings. Australasian Journal of Educational Technology 28, 2: 295 - 314. https://doi.org/10.14742/ajet.875

Rambe, P. \& D. Ng'ambi 2011. Towards an Information Sharing Pedagogy: A Case of Using Facebook in a Large First Year Class. Informing Science. The International Journal of an Emerging Transdiscipline 14: 61 - 89. https://doi.org/10.28945/1391

Sanders, J.T. 1997. An Ontology of Affordances. Ecological Psychology 9, 1:

97 - 112. https://doi.org/10.1207/s15326969eco0901_4

Scarantino, A. 2003. Affordances Explained. Philosophy of Science 70, 5: 949 - 961. https://doi.org/10.1086/377380 
Teclehaimanot, B. \& H. Torey 2011. Student - Teacher Interaction on Facebook: What Students Find Appropriate. TechTrends 55, 3: 19 - 30. https://doi.org/10.1007/s11528-011-0494-8

Turvey, M.T. 1992. Affordances and Prospective Control: An Outline of the Ontology. Ecological Psychology 4, 3: 173 - 187.

https://doi.org/10.1207/s15326969eco0403_3

Wang, Q., W.L. Huay, C.L. Quek, Y. Yang \& M. Liu 2012. Using the Facebook Group as a Learning Management System: An Exploratory Study. British Journal of Educational Technology 43, 3: 428 - 438. https://doi.org/10.1111/j.1467-8535.2011.01195.x

Williams, R. \& D. Edge 1996. The Social Shaping of Technology. Research Policy 25, 6: 865 - 899. https://doi.org/10.1016/0048-7333(96)00885-2

Williams, R., R. Karousou \& J. Mackness 2011. Emergent Learning and Learning Ecologies in Web 2.0. The International Review of Research in Open and Distance Learning 12, 3: 39 - 59.

https://doi.org/10.19173/irrodl.v12i3.883

Craig N. Blewett School of Management, IT \& Governance University of KwaZulu-Natal Durban South Africa blewett@ukzn.ac.za

Wayne Hugo School of Education University of KwaZulu-Natal Durban South Africa hugow@ukzn.ac.za 